Research Article

\title{
Comparative cytogenetics in three Melipona species (Hymenoptera: Apidae) with two divergent heterochromatic patterns
}

\author{
Marina Souza da Cunha ${ }^{1}$, Natália Martins Travenzoli ${ }^{1}$, Riudo de Paiva Ferreira ${ }^{1,2}$, Edson Kuatelela \\ Cassinela $^{1,3}$, Henrique Barbosa da Silva ${ }^{1}$, Francisco Plácido Magalhães Oliveira ${ }^{4}$, Tânia Maria Fernandes \\ Salomão ${ }^{1}$ and Denilce Meneses Lopes ${ }^{1}$ (iD \\ ${ }^{1}$ Laboratório de Biologia Molecular de Insetos, Departamento de Biologia Geral, Universidade Federal de \\ Viçosa, Viçosa, MG, Brazil. \\ ${ }^{2}$ Faculdade de Ciências Gerenciais de Manhuaçu, Campus Alfa Sul, Manhuaçu, MG, Brazil. \\ ${ }^{3}$ Camargo Cancer Center, Centro Internacional de Ensino e Pesquisa (CIPE), São Paulo, SP, Brazil. \\ ${ }^{4}$ Instituto de Medicina Veterinária, Universidade Federal do Pará, Campus de Castanhal, Castanhal, PA, \\ Brazil.
}

\begin{abstract}
The genus Melipona is subdivided into four subgenera based on morphological characteristics, and two groups based on cytogenetic patterns. The cytogenetic information on this genus is still scarce, therefore, the goal of this study was to characterize Melipona paraensis, Melipona puncticollis, and Melipona seminigra pernigra using the following techniques: C-banding, DAPI/CMA ${ }_{3}$ fluorochromes, and FISH with an $18 \mathrm{~S}$ rDNA probe. Melipona paraensis $(2 n=18)$ and $M$. seminigra pernigra $(2 n=22)$ were classified as high heterochromatin content species (Group II). Their euchromatin is restricted to the ends of the chromosomes and is $\mathrm{CMA}_{3}{ }^{+}$; the $18 \mathrm{~S}$ rDNA probe marked chromosome pair number 4. Melipona puncticollis $(2 n=18)$ is a low heterochromatin content species (Group I) with chromosome pair number 1 marked with $\mathrm{CMA}_{3}$ and $18 \mathrm{~S}$ rDNA. Low heterochromatin content is a putative ancestral karyotype in this genus and high content is not a monophyletic trait (Melikerria presents species with both patterns). Differences concerning the karyotypic characteristics can be observed among Melipona species, revealing cytogenetic rearrangements that occurred during the evolution of this genus. Studies in other species will allow us to better understand the processes that shaped the chromatin evolution in Melipona.
\end{abstract}

Keywords: Chromosomal evolution, DAPI/CMA 3 fluorochromes, Fluorescent in situ Hybridization (FISH), heterochromatin, Meliponini.

Received: October 26, 2017; Accepted: February 23, 2018.

\section{Introduction}

Species belonging to the Meliponini tribe are also known as stingless bees. These highly eusocial bees are of pantropical distribution and are important both economically and ecologically. They produce honey and propolis, pollinate a variety of cultivated and native crops, and play an important role as providers of ecosystem services (Kerr et al., 1996; Heard, 1999; Cortopassi-Laurino et al., 2006; Michener, 2007). In the Neotropics, Meliponini is composed of 33 genera with approximately 417 valid species (Camargo and Pedro, 2013). Among these genera, Melipona Illiger 1806 is the most species-rich genus in this tribe (Silveira et al., 2002), represented by 73 described

Send correspondence to Denilce M. Lopes. Departamento de Biologia Geral, Universidade Federal de Viçosa, Av. P. H. Rolfs, s/n, Centro, Viçosa, 36570-900, MG, Brazil. E-mail: denilce.lopes@ufv.br. species of which 43 occur in Brazil, and it is subdivided into four subgenera based on morphological characteristics: Eomelipona, Melipona stricto sensu, Michmelia, and Melikerria (Camargo and Pedro, 2013). It is important to highlight that a revision is needed, since Eomelipona is the only subgenus that was not recovered as a monophyletic clade in a molecular phylogenetic analysis (Ramírez et al., 2010; Rasmussen and Cameron, 2010).

Cytogenetic studies on 22 Melipona species indicate a preserved autosome diploid number of $2 n=18$ chromosomes in most of the species studied so far, with Melipona seminigra merillae Cockerell, 1919 being the exception, showing $2 n=22$ chromosomes (reviewed in Tavares et al., 2017). Despite the conservatism in the diploid number, the Melipona species have a divergent pattern regarding heterochromatin content, and defined through C-banding technique it can be subdivided into two groups: Group I is comprised of species with a low content of heterochro- 
matin, while Group II is comprised of species with a high heterochromatin content (Rocha and Pompolo, 1998; Rocha et al., 2002, 2003; Lopes et al., 2008, 2011). In this context, the subgenera Eomelipona and Melipona stricto sensu are comprised only of species with a low content of heterochromatin, Michmelia only of species with a high content, while Melikerria has species with both patterns. The cytogenetic data available on the genus Melipona re- garding chromosome number, C-banding, $\mathrm{CMA}_{3}$, and $18 \mathrm{~S}$ rDNA patterns is revised in Table 1.

The goal of this study was to describe the cytogenetic characteristics (chromosomal number, heterochromatin content, $\mathrm{DAPI} / \mathrm{CMA}_{3}$ fluorochromes, and $18 \mathrm{~S}$ rDNA patterns) of three Melipona species (Melipona paraensis Ducke, 1916, Melipona puncticollis Friese, 1902, and Melipona seminigra pernigra Friese, 1903), and to compile

Table 1 - Cytogenetic data available on 22 Melipona species regarding their chromosome number (karyotypic formula), C-banding (high or low content), $\mathrm{CMA}_{3}$ and $18 \mathrm{~S}$ rDNA patterns. Species were assigned to subgenera based on the Moure's catalogue.

\begin{tabular}{|c|c|c|c|c|c|c|}
\hline Subgenus & Species & $\begin{array}{l}\text { Chromosome } \\
\text { Number }\end{array}$ & C-Banding & $\mathrm{CMA}_{3}$ & $18 \mathrm{~S}$ rDNA & References \\
\hline \multirow[t]{4}{*}{ Eomelipona } & M. asilvai & $2 n=18$ & Low content & 2 interstitial markings & $\begin{array}{l}2 \text { interstitial } \\
\text { markings }\end{array}$ & $\begin{array}{l}\text { Rocha and Pompolo, 1998; } \\
\text { Rocha et al., 2002; Rocha } \\
\text { et al., } 2007\end{array}$ \\
\hline & M. bicolor & $2 n=18$ & Low content & 2 interstitial markings & - & Rocha and Pompolo, 1998 \\
\hline & M. marginata & $2 n=18$ & Low content & 2 interstitial markings & $\begin{array}{l}2 \text { interstitial } \\
\text { markings }\end{array}$ & $\begin{array}{l}\text { Rocha and Pompolo, 1998; } \\
\text { Maffei et al., 2001; Rocha } \\
\text { et al., } 2007\end{array}$ \\
\hline & M. puncticollis & $\begin{array}{l}2 n=18 \\
(2 m+14 s m+2 a)\end{array}$ & Low content & 2 interstitial markings & $\begin{array}{l}2 \text { interstitial } \\
\text { markings }\end{array}$ & Present study \\
\hline \multirow[t]{2}{*}{ Melikerria } & M. fasciculata & $2 n=18$ & High content & $\begin{array}{l}\text { Terminal marks on all } \\
\text { chromosomes }\end{array}$ & $\begin{array}{l}2 \text { terminal } \\
\text { markings }^{\dagger}\end{array}$ & $\begin{array}{l}\text { Rocha et al, 2002; Lopes } \\
\text { et al., } 2011\end{array}$ \\
\hline & M. quinquefasciata & $2 n=18^{\ddagger}$ & Low content & 2 interstitial markings & - & Rocha et al., 2007 \\
\hline \multirow[t]{4}{*}{ Melipona } & M. favosa & $\begin{array}{l}2 n=18 \\
(12 m+4 s m+2 a)\end{array}$ & - & - & - & Hoshiba, 1988 \\
\hline & M. mandacaia & $\begin{array}{l}2 n=18 \\
(2 \mathrm{~m}+14 \mathrm{sm}+2 \mathrm{a})\end{array}$ & Low content & 2 interstitial markings & - & Rocha et al., 2003 \\
\hline & M. quadrifasciata & $\begin{array}{l}2 n=18 \\
(4 m+12 s m+2 a)\end{array}$ & Low content & 2 interstitial markings & - & Rocha and Pompolo, 1998 \\
\hline & M. subnitida & $2 n=18$ & Low content & 2 interstitial markings & - & $\begin{array}{l}\text { Rocha et al., 2002; Rocha } \\
\text { et al., } 2007\end{array}$ \\
\hline \multirow[t]{12}{*}{ Michmelia } & M. capixaba & $2 n=18$ & High content & $\begin{array}{l}\text { Terminal marks on all } \\
\text { chromosomes }\end{array}$ & - & $\begin{array}{l}\text { Rocha and Pompolo, 1998; } \\
\text { Rocha et al., } 2002\end{array}$ \\
\hline & M. captiosa & $2 n=18$ & High content & - & - & Rocha and Pompolo, 1998 \\
\hline & M. crinita & $2 n=18$ & High content & $\begin{array}{l}\text { Terminal marks on all } \\
\text { chromosomes }\end{array}$ & - & Rocha et al., 2002 \\
\hline & M. flavolineata & $2 n=18$ & High content & $\begin{array}{l}\text { Terminal marks on all } \\
\text { chromosomes }\end{array}$ & - & Lopes et al., 2011 \\
\hline & M. fuliginosa & $2 n=18$ & High content & $\begin{array}{l}\text { Terminal marks on all } \\
\text { chromosomes }\end{array}$ & - & Lopes et al., 2011 \\
\hline & M. fuscopilosa & $2 n=18$ & High content & $\begin{array}{l}\text { Terminal marks on all } \\
\text { chromosomes }\end{array}$ & - & $\begin{array}{l}\text { Rocha and Pompolo, 1998; } \\
\text { Rocha et al., } 2002\end{array}$ \\
\hline & M. mondury & $2 n=18$ & High content & $\begin{array}{l}\text { Terminal marks on all } \\
\text { chromosomes }\end{array}$ & - & Lopes et al., 2008 \\
\hline & M. paraensis & $2 n=18$ & High content & $\begin{array}{l}\text { Terminal marks on all } \\
\text { chromosomes }\end{array}$ & $\begin{array}{l}2 \text { terminal } \\
\text { markings }\end{array}$ & Present study \\
\hline & M. rufiventris & $2 n=18^{*}$ & High content & $\begin{array}{l}\text { Terminal marks on all } \\
\text { chromosomes }\end{array}$ & - & Lopes et al., 2008 \\
\hline & M. scutellaris & $2 n=18$ & High content & $\begin{array}{l}\text { Terminal marks on all } \\
\text { chromosomes }\end{array}$ & - & $\begin{array}{l}\text { Rocha and Pompolo, 1998; } \\
\text { Rocha et al., } 2002\end{array}$ \\
\hline & M. seminigra merrillae & $2 n=22$ & Low content? $?^{\S}$ & - & - & Francini et al., 2011 \\
\hline & M. seminigra pernigra & $2 n=22$ & High content & $\begin{array}{l}\text { Terminal marks on all } \\
\text { chromosomes }\end{array}$ & $\begin{array}{l}2 \text { terminal } \\
\text { markings }\end{array}$ & Present study \\
\hline
\end{tabular}

\footnotetext{
${ }^{*}$ Ag-NOR data.

${ }^{\dagger}$ M. compressipes in the paper of Rocha et al. (2002) is indeed M. fasciculata (Tavares et al., 2017).

${ }^{\ddagger} \mathrm{B}$ chromosomes were reported in these two species.

${ }^{\S}$ Reevaluated as high content. More details are given in the text.
} 
the cytogenetic data available for this taxon in order to identify the chromosomal variation that is characteristic for each Melipona Group (I and II), as well as to understand the role of these regions in the evolution of chromosomes in the genus.

\section{Material and Methods}

The three Melipona species ( $M$. paraensis, $M$. puncticollis, and M. seminigra pernigra) were collected in Altamira, state of Pará, Brazil. The specimens were identified by Sílvia Regina de Menezes Pedro (Universidade de São Paulo, Ribeirão Preto, Brazil), and deposited in the scientific collection of the Apiário Central at Universidade Federal de Viçosa, Viçosa, Minas Gerais, Brazil. Mitotic chromosomes were obtained from cerebral ganglia of larvae in the final defecation stage (Imai et al., 1988). The conventional staining was done using Giemsa diluted in Sorensen buffer in a 1:30 proportion, and at least 25 larvae of each species were analyzed. The chromosomes were classified following the arm ratios given by Levan et al. (1964). Heterochromatin was visualized through C-banding (Sumner, 1972) and digital images of the metaphases were taken in a BX53F Olympus microscope equipped with a DP73F Olympus camera, using CellSens imaging software.

Sequential staining with the fluorochromes 4'-6-diamindino-2-phenylindole (DAPI) and chromomycin $\mathrm{A}_{3}$ $\left(\mathrm{CMA}_{3}\right)$ was performed following the method of Schweizer (1980). Fluorescent in situ Hybridization (FISH) followed the protocol described by Pinkel et al. (1986) using a ribosomal 18S rDNA probe isolated from M. mondury obtained through Polymerase Chain Reaction (PCR) using the following primers: 5'-TAATTCCAGCTCCAATAG-3' and 5'-CCACCCATAGAATCAAGA-3'. This probe was labeled by an indirect method using digoxigenin-11-dUTP (Roche Applied Science), and the signal was detected with anti-digoxigenin-rhodamine (Roche Applied Science). Digital images of the fluorescence images were captured in a BX53F Olympus microscope equipped with an MX10 Olympus camera using CellSens imaging software. An average of 10 metaphases was analyzed to determine the cytogenetic patterns revealed by the different techniques used in this study.

\section{Results}

The diploid chromosome number of $M$. paraensis was defined as $2 n=18$ (Figure 1a). C-banding revealed that

a)
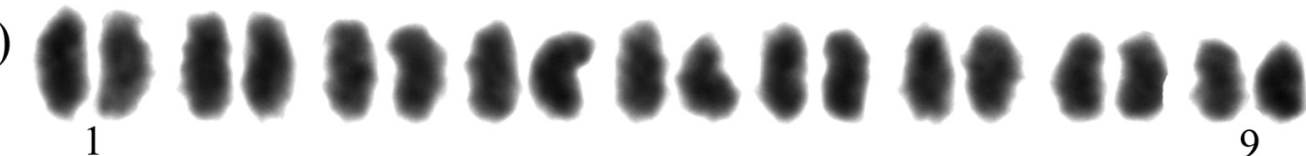

b)
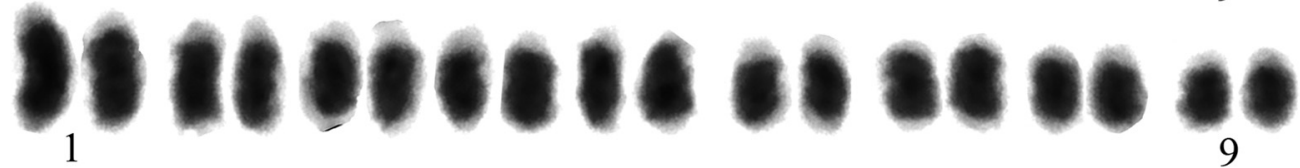

c)
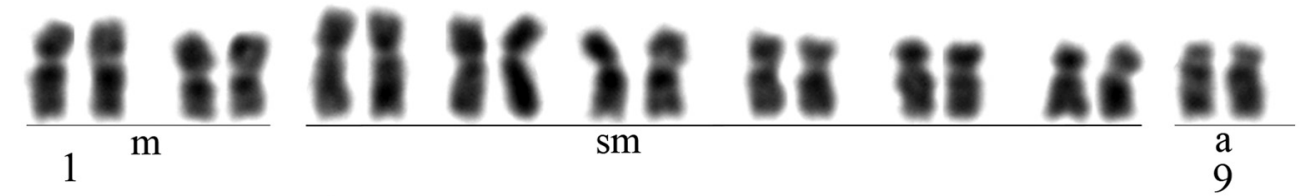

d)
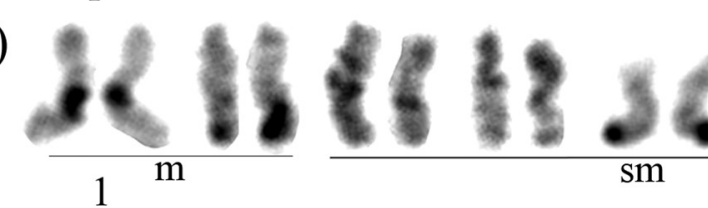

e)
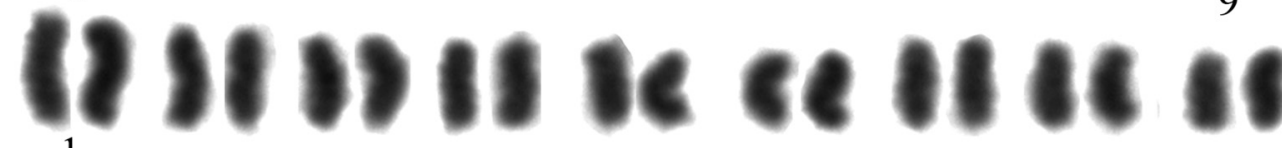

f)
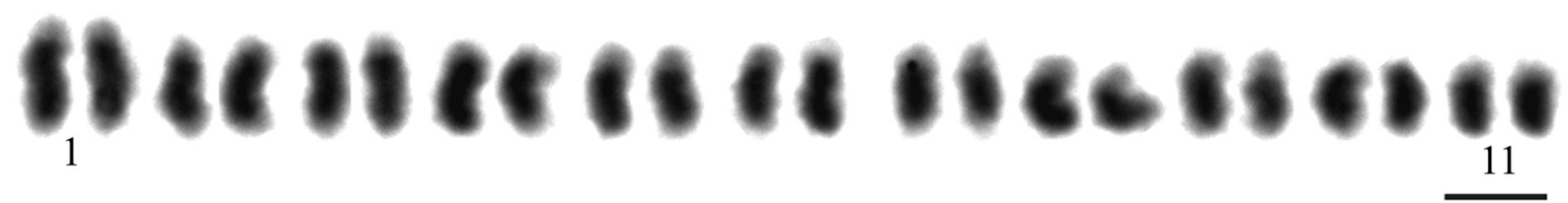

Figure 1 - Karyotypes of Melipona paraensis (a - Giemsa-stained, b - C-banding); Melipona puncticollis (c - Giemsa-stained, d - C-banding); and Melipona seminigra pernigra (e - Giemsa-stained, f - C-banding). Scale bar $=5 \mu \mathrm{m}$. 
the major part of each chromosome is comprised of heterochromatin. This hindered the visualization of centromeres, and hence it was not possible to define the karyotypic formula (Figure 1b). The DAPI/CMA 3 analysis indicated that the heterochromatin is DAPI ${ }^{+}$(Figure $2 \mathrm{a}$ and Figure S1a-c), while $\mathrm{CMA}_{3}{ }^{+}$marked all the extremities of the chromosomes corresponding to the euchromatin region (Figure 2b). FISH with $18 \mathrm{~S}$ rDNA probe marked chromosome pair number 4 in its terminal position (Figure $3 \mathrm{a}$ ).

The diploid chromosome number of $M$. puncticollis was defined as $2 n=18$ and its karyotypic formula as $2 n=$ $2 \mathrm{~m}+14 \mathrm{sm}+2 \mathrm{a}$ (Figure 1c). C-banding indicated a low content of heterochromatin that is restricted to the pericentromeric region of chromosome pair numbers 1, 3, 6, 9, and the subtelomeric region of the long arms of chromosome pair numbers 2, 4, 5 and 7, while chromosome pair number 8 is completely euchromatic (Figure 1d). Sequential staining with DAPI/CMA $\mathrm{CM}_{3}$ fluorochromes indicated strong $\mathrm{DAPI}^{+}$bands corresponding to the heterochromatin region (Figure $2 \mathrm{c}$ ), while $\mathrm{CMA}_{3}$ marked the interstitial region of chromosome pair number 1 (Figure 2d). The same result was found with the $18 \mathrm{~S}$ rDNA FISH probe (Figure 3b).

The diploid chromosome number of $M$. seminigra pernigra was defined as $2 n=22$ (Figure 1e). C-banding revealed that the majority of each chromosome is composed of heterochromatin, hindering the visualization of the centromeres, so it was not possible to define the karyotypic formula (Figure 1f). DAPI/CMA 3 analysis indicated that the heterochromatin is $\mathrm{DAPI}^{+}$(Figure 2e and Figure S1d-f). $\mathrm{CMA}_{3}{ }^{+}$marked all the extremities of the chromosomes corresponding to the euchromatin region, and we could identify one chromosome pair that strongly stained with $\mathrm{CMA}_{3}$ fluorochrome (Figure 2f). FISH with the 18S rDNA probe marked chromosome pair number 4 in its terminal position (Figure 3c).

\section{Discussion}

The three species analyzed in this study presented distinct chromosome numbers: M. (Michmelia) paraensis and M. (Eomelipona) puncticollis presented $2 n=18$ chromosomes, while $M$. (Michmelia) seminigra pernigra showed $2 n=22$ chromosomes. The autosomal chromosome number that prevails in the genus Melipona is $2 n=18$, but a few exceptions can be found, such as in M. (Michmelia) seminigra merillae that also has $2 n=22$, and Melipona (Melikerria) quinquefasciata Lepeletier, 1836 and Melipona (Michmelia) rufiventris Lepeletier, 1836, both of which have $2 n=18$ autosomal chromosomes, but they present variation with respect to the number of $\mathrm{B}$ chromosomes found in different populations (reviewed in Tavares et al., 2017).

Regardless of the conservatism in the diploid number, differences concerning the karyotypic formula and heterochromatin content could be observed among species, re- vealing cytogenetic rearrangements that have occurred during the evolution of the genus. Changes in the karyotypic formula among species belonging to Group I indicate the occurrence of pericentric inversions that altered the number of metacentric and submetacentric chromosomes in this group: Melipona favosa Fabricius, $1798(2 n=12 \mathrm{~m}+4 \mathrm{sm}+$ 2a) (Hoshiba, 1988), Melipona mandacaia Smith, 1863 (2n $=2 \mathrm{~m}+14 \mathrm{sm}+2 \mathrm{a})($ Rocha et al., 2003), M. puncticollis $(2 n$ $=2 \mathrm{~m}+14 \mathrm{sm}+2 \mathrm{a}$ ) (present study), and Melipona quadrifasciata Lepeletier, $1836(2 n=4 \mathrm{~m}+12 \mathrm{sm}+2 \mathrm{a})$ (Silva et al., 2012). In Group II species, the high heterochromatin content masks the position of the centromere, and therefore, makes it difficult to identify the morphology of the chromosomes to define the karyotypic formula of these species. This is a common trait among the Melipona species belonging to Group II, rather than an issue related to the quality of the metaphases (Rocha et al., 2002; Lopes et al., 2008, 2011).

In the species analyzed in this study, M. puncticollis is a low heterochromatin content species, while $M$. paraensis and $M$. seminigra pernigra are high heterochromatin content species (Figure 1). The first description of the C-banding pattern on $M$. seminigra merrilae indicated this subspecies as part of Group I, with low heterochromatin content (Francini et al., 2011), but analyzing the images from that publication, the pattern seems to be very similar to the high heterochromatin content species, as it was not possible to visualize the centromeres, and they had heterochromatin as the predominant constituent of the chromosomes. Ongoing cytogenetic studies on this subspecies confirm that $M$. seminigra merrillae, as well as $M$. seminigra pernigra are high heterochromatin content subspecies belonging to Group II (unpublished data).

In eusocial bees, the heterochromatin is usually AT-rich $\left(\mathrm{DAPI}^{+}\right)$(Brito et al., 2003; Rocha et al., 2003; Lopes et al., 2011; Godoy et al., 2013), and this is a pattern shared by Melipona species with both low and high heterochromatin content (Figure 2). $\mathrm{CMA}_{3}{ }^{+}$positive bands are another characteristic used to distinguish Groups I and II in this genus (Table 1): Group I species have only one chromosome pair $\mathrm{CMA}_{3}{ }^{+}$marked in its interstitial position, and this chromosome pair is usually related to the nucleolar organizing region (NOR) (Rocha et al., 2002), indicating that the NOR is CG-rich in this group; Group II species have $\mathrm{CMA}_{3}{ }^{+}$terminal markings on all of the chromosomes corresponding to the euchromatin, indicating that these regions are CG-rich, and in some cases it is possible to identify one pair with the brightest mark as associated with ribosomal cistrons, as for instance in $M$. seminigra pernigra (Figure $2 \mathrm{~F}$ ) and other high heterochromatic content species (Lopes et al., 2008, 2011). It is interesting to note that the solitary bee Melitoma segmentaria Fabricius, 1804 has the opposite pattern, as the euchromatic portion of the chromosomes are $\mathrm{CMA}_{3}{ }^{-}$and the heterochromatic ones are $\mathrm{CMA}_{3}^{+}$(Cristiano et al., 2014). Other solitary bees, 
such as Euglossa townsendi Cockerell, 1904 and Euglossa carolina Linnaeus, 1758), have the same cytogenetic diver- gence as Melipona with regard to the heterochromatin content (species with low and high heterochromatin content),
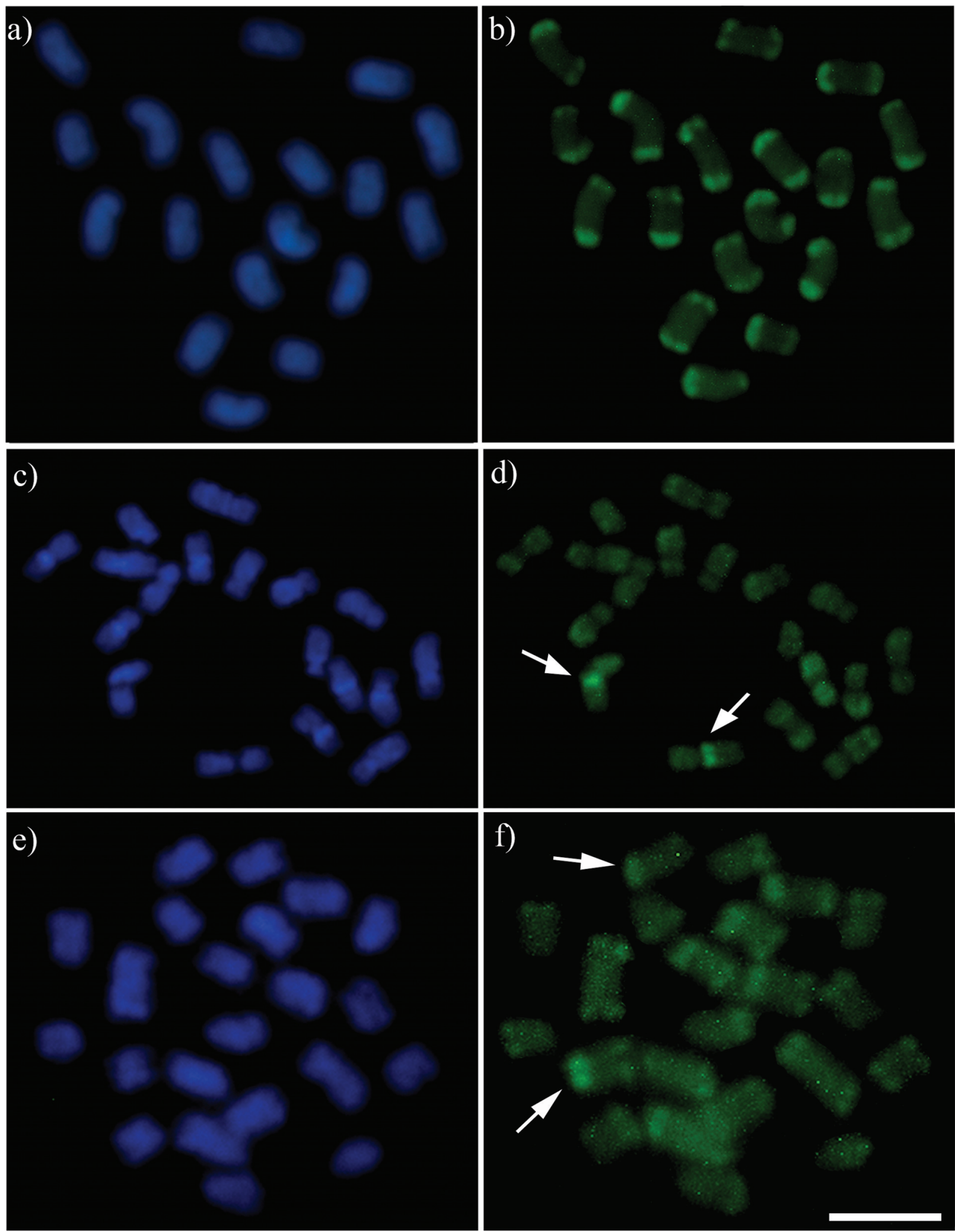

Figure 2 - Sequential staining with DAPI/CMA fluorochromes: Melipona paraensis (a - DAPI, b - $\left.\mathrm{CMA}_{3}\right)$; Melipona puncticollis (c - DAPI, d - CMA $)$; and Melipona seminigra pernigra (e - DAPI, $\mathrm{f}-\mathrm{CMA}_{3}$ ). The arrows indicate the organizing region of the nucleoli. Scale bar $=5 \mu \mathrm{m}$. 

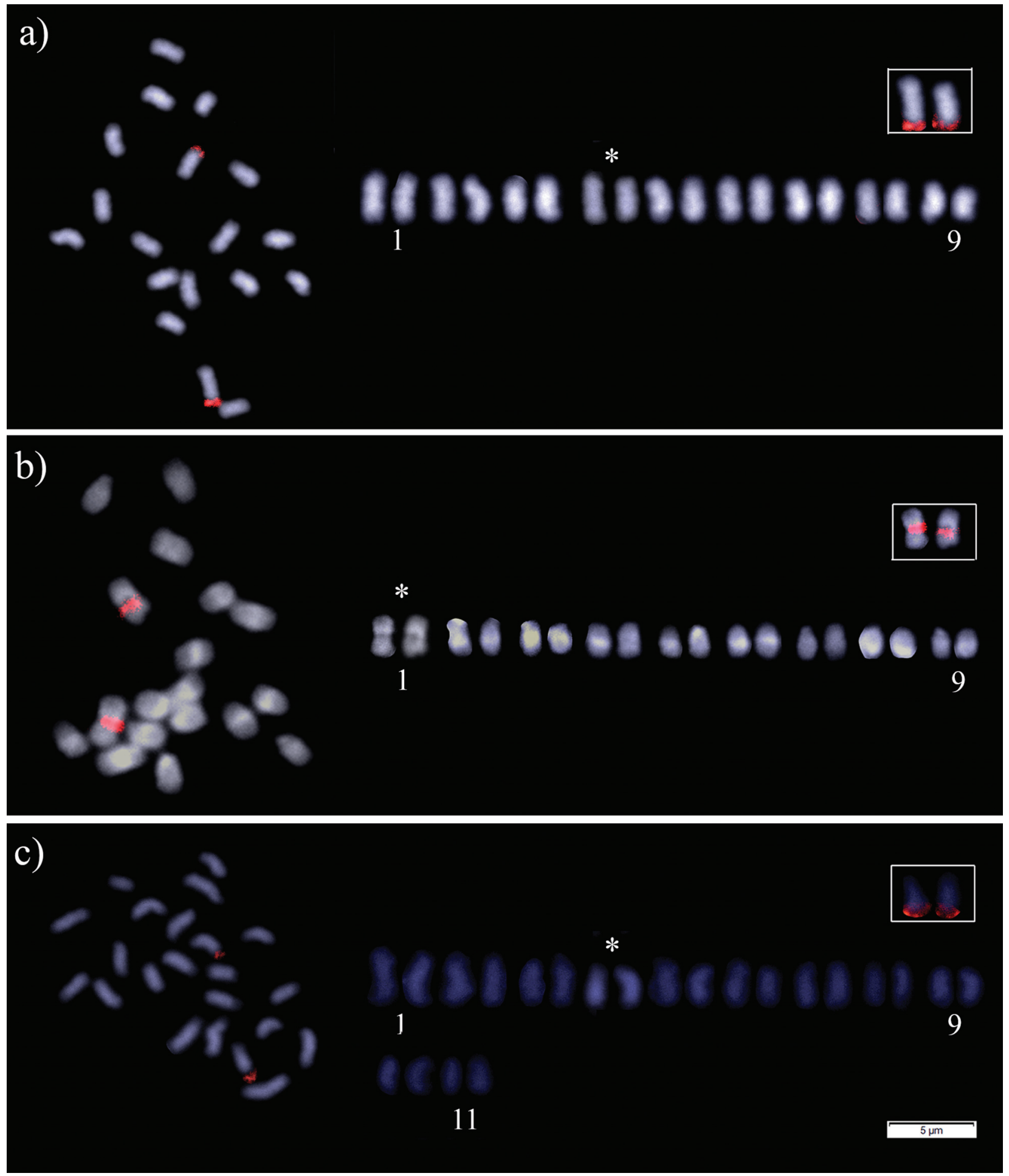

Figure 3 - Fluorescent in situ hybridization (FISH) pattern with 18S rDNA probe: metaphase cells and arranged karyotype of (a) Melipona paraensis; (b) Melipona puncticollis; and (c) Melipona seminigra pernigra. ${ }^{*}$ denotes chromosome pair marked by the probe indicated in the box. Scale bar $=5 \mu \mathrm{m}$.

but they have unique $\mathrm{CMA}_{3}$ accumulation patterns, showing that the heterochromatin is heterogeneous with respect to its composition, with some blocks rich in AT and others rich in CG (Fernandes et al., 2013), highlighting the diversity of the patterns observed among bees.
To this date, there is only one report that has used FISH to confirm the position of the NORs with an $18 \mathrm{~S}$ rDNA FISH probe; this was done in Melipona fasciculata Smith, 1854 (Rocha et al., 2002, revised in Tavares et al., 2017). Together with our study, it seems that only one pair 
of chromosomes labeled with this probe, which can be considered as a conserved characteristic in this genus (Figure 3). Studies applying ribosomal probes in bees are still scarce, but analyses combining Ag-NOR, $\mathrm{CMA}_{3}{ }^{+}$bands, and FISH $18 \mathrm{~S}$ rDNA techniques have been used to identify NORs in different Meliponini species (Rocha et al., 2002; Brito et al., 2005; Duarte et al., 2009; Krinski et al., 2010; Lopes et al., 2011; Godoy et al., 2013; Miranda et al., 2013). Based on these three different techniques it can be inferred that having only one pair of NORs is a conserved characteristic in Melipona (Table 1).

Regardless of the conservatism in the number of markings, the position of the $18 \mathrm{~S}$ rDNA cistrons can be used to differentiate Groups I and II in Melipona, as they are interstitial in low content species and terminal in high content ones (Table 1). Independent of the technique applied, the literature indicates pair number 1 as the NOR bearer in this genus. For: Melipona asilvai Moure, 1971, M. mandacaia, and Melipona marginata Moure, 1992 this was inferred by Ag-NOR (Maffei et al., 2001; Rocha et al., 2002, 2003). For Melipona bicolor Lepeletier, 1836, Melipona capixaba Moure and Camargo, 1994, Melipona mondury Smith, 1863, M. quadrifasciata, $M$. quinquefasciata, $M$. rufiventris, and Melipona subnitida Ducke, 1910 the identification was done by $\mathrm{CMA}_{3}$ fluorochrome (Rocha et al., 2007; Lopes et al., 2008), and for M. fasciculata it was identified by FISH with a ribosomal probe (Rocha et al., 2002 revised in Tavares et al., 2017). However, in our study only the low content species M. puncticollis had the first pair as the NOR bearer, while the high content species $M$. paraensis and M. seminigra pernigra had pair number 4 marked with the 18S rDNA probe (Figure 3), highlighting another distinct characteristic between Groups I and II. We argue that none of the cited studies above arranged the karyotype. Hence in metaphase cells, the terminal location of the probe in the high content species might have given the impression of a bigger chromosome (see Figure 3).

Despite being polyphyletic, basal Eomelipona species group together with Melipona stricto sensu (Ramírez et al., 2010), and this clade is composed of species with low heterochromatin content (Table 1), indicating that this is the plesiomorphic characteristic of the genus, while high heterochromatin content appeared more than once during the evolution and diversification of this taxon, emerging in both Melikerria and Michmelia subgenera. As we could observe both heterochromatin patterns in Melikerria (Table 1), the classification of the Melipona species into low and high heterochromatin content species did not form natural groups and did not represent monophyletic clades in the phylogenetic analysis.

The current study aimed to describe three Melipona species with divergent patterns of heterochromatin accumulation, arguing that a karyotype with low heterochromatin content is a putative ancestral karyotype in this genus and that high heterochromatin content is not a monophy- letic characteristic. We also contributed with new cytogenetic data on Groups I and II, highlighting the cytogenetic rearrangements that occurred during the chromosome evolution in this major stingless bee genus. Finally, we emphasize the importance of cytogenetic analyses to evidence the chromosomal rearrangements that occurred during the evolution of different species (Imai et al., 1994; Menezes et al., 2014). Studies in other species will allow us to better understand the processes that shaped chromatin evolution in Melipona.

\section{Acknowledgments}

The authors wish to thank NORTE ENERGIA and BIOTA for logistical support during field work done in Altamira, state of Pará, Brazil. Financial support is acknowledged from Conselho Nacional de Desenvolvimento Científico e Tecnológico (CNPq), Coordenação de Aperfeiçoamento de Pessoal de Nível Superior (CAPES), Fundação de Amparo à Pesquisa do Estado de Minas Gerais (FAPEMIG), and Fundação Amazônia de Amparo a Estudos e Pesquisas do Pará (FAPESPA).

\section{References}

Brito RM, Caixeiro APA, Pompolo SG and Azevedo GG (2003) Cytogenetic data of Partamona peckolti (Hymenoptera, Apidae, Meliponini) by $\mathrm{C}$ banding and fluorochrome staining with DA/ $\mathrm{CMA}_{3}$ and DA/DAPI. Genet Mol Biol 26:5357.

Brito RM, Pompolo SG, Magalhães MFM, Barros EG and Sakamoto-Hojo ET (2005) Cytogenetic characterization of two Partamona species (Hymenoptera, Apidae, Meliponini) by fluorochrome staining and localization of $18 \mathrm{~S}$ rDNA clusters by FISH. Cytologia 70:373-380.

Camargo JMF and Pedro SRM (2013) Meliponini Lepeletier, 1836. In: Moure JS, Urban D and Melo GAR (eds) Catalogue of Bees (Hymenoptera, Apoidea) in the Neotropical Region. Sociedade Brasileira de Entomologia, Curitiba, pp. 272-578.

Cortopassi-Laurino M, Imperatriz-Fonseca VL, Roubik DW, Dolin A, Heard T, Aguilar I, Venturieri GC, Eardley C and Nogueira-Neto P (2006) Global meliponiculture: Challenges and opportunities. Apidologie 37:275-292.

Cristiano MP, Simoes TG, Lopes DM and Pompolo SG (2014) Cytogenetics of Melitoma segmentaria (Fabricius, 1804) (Hymenoptera, Apidae) reveals differences in the characteristics of heterochromatin in bees. Comp Cytogenet 8:223231.

Duarte OMP, Martins CCC and Waldschmidt AM (2009) Occurrence of multiple nucleolus organizer regions and intraspecific karyotype variation in Scaptotrigona xanthotricha Moure (Hymenoptera, Meliponini). Genet Mol Res 8:831839.

Fernandes A, Werneck HA, Pompolo SG and Lopes DM (2013) Evidence of separate karyotype evolutionary pathway in Euglossa orchid bees by cytogenetic analyses. An Acad Bras Cienc 85:937-944.

Francini IB, Gross MC, Nunes-Silva CG and Carvalho-Zilse GA (2011) Cytogenetic analysis of the Amazon stingless bee 
Melipona seminigra merrillae reveals different chromosome number for the genus. Sci Agr 68:592-593.

Godoy DC, Ferreira RP and Lopes DM (2013) Chromosomal variation and cytogenetics of Plebeia lucii and P. phrynostoma (Hymenoptera: Apidae). Fla Entomol 96:1559-1566.

Heard TA (1999) The role of stingless bees in crop pollination. Annu Rev Entomol 44:183-206.

Hoshiba H (1988) Karyological analysis of a stingless bee, Melipona favosa (Apidae, Hymenoptera). Cytologia 53:153156.

Imai HT, Taylor RW, Crosland MW and Crozier RH (1988) Modes of spontaneous chromosomal mutation and karyotype evolution in ants with reference to the minimum interaction hypothesis. Jpn J Genet 63:159-185.

Imai HT, Taylor RW and Crozier RH (1994) Experimental bases for the minimum interaction theory. I. Chromosome evolution in ants of the Myrmecia pilosula species complex (Hymenoptera: Formicidae: Myrmeciinae). Jpn J Genet 69:137-182.

Kerr WE, Carvalho GA and Nascimento VA (1996) Abelha Uruçu - Biologia, Manejo e Conservação. Fundação Acangaú, Belo Horizonte, 157 p.

Krinski D, Fernandes A, Rocha MP and Pompolo SG (2010) Karyotypic description of the stingless bee Oxytrigona cf. flaveola (Hymenoptera, Apidae, Meliponina) of a colony from Tangará da Serra, Mato Grosso State, Brazil. Genet Mol Biol 33:494-498.

Levan A, Fredga K and Sandberg AA (1964) Nomenclature for centromeric position on chromosomes. Hereditas 52:201220.

Lopes DM, Pompolo SG, Campos LAO and Tavares MG (2008) Cytogenetic characterization of Melipona rufiventris Lepeletier 1836 and Melipona mondury Smith 1863 (Hymenoptera, Apidae) by $\mathrm{C}$ banding and fluorochromes staining. Genet Mol Biol 31:49-52.

Lopes DM, Fernandes A, Praça-Fontes MM, Werneck HDA, Resende HC and Campos LAO (2011) Cytogenetics of three Melipona species (Hymenoptera, Apidae, Meliponini). Sociobiology 58:185-194.

Maffei EMD, Pompolo SG, Silva-Junior JC, Caixeiro APA, Rocha MP and Dergam JA (2001) Silver staining of nucleolar organizer regions (NORs) in some species of Hymenoptera (bees and parasitic wasps) and Coleoptera (lady beetle). Cytobios 104:119-125.

Menezes RST, Carvalho JPSO, Silva TS, Somovilla A and Costa MA (2014) Evolutionary trends in the chromosome numbers of swarm-founding social wasps. Insectes Soc 61:385-393.

Michener CD (2007) The bees of the world. 2nd edition. The Johns Hopkins University Press, Baltimore, 972 p.

Miranda RV, Fernandes A and Lopes DM (2013) Karyotype description of Cephalotrigona femorata Smith (Hymenoptera:
Apidae) and the C-banding pattern as a specific marker for Cephalotrigona. Sociobiology 60:125-127.

Pinkel D, Straume T and Gray JW (1986) Cytogenetic analysis using quantitative, high sensitivity, fluorescence hybridization. Proc Natl Acad Sci U S A 83:2934-2938.

Ramírez SR, Nieh JC, Quental TB, Roubik DW, ImperatrizFonseca VL and Pierce NE (2010) A molecular phylogeny of the stingless bee genus Melipona (Hymenoptera: Apidae). Mol Phylogenet Evol 56:519-525.

Rasmussen C and Cameron SA (2010) Global stingless bee phylogeny supports ancient divergence, vicariance, and long distance dispersal. Biol J Linn Soc 99:206-232.

Rocha MP and Pompolo SG (1998) Karyotypes and heterochromatin variation (C-bands) in Melipona species (Hymenoptera, Apidae, Meliponinae). Genet Mol Biol 21:41-45.

Rocha MP, Pompolo SG, Dergam JA, Fernandes A and Campos LAO (2002) DNA characterization and karyotypic evolution in the bee genus Melipona (Hymenoptera, Meliponini). Hereditas 136:19-27.

Rocha MP, Cruz MP, Fernandes A, Waldschmidt AM, SilvaJunior JC and Pompolo SG (2003) Longitudinal differentiation in Melipona mandacaia (Hymenoptera, Meliponini) chromosomes. Hereditas 138:133-137.

Rocha MP, Pompolo SG, Fernandes A and Campos LAO (2007) Melipona: Six decade of cytogenetic. Biosci J 23:111-117.

Schweizer D (1980) Simultaneous fluorescent staining of R bands and specific heterochromatic regions (DA - DAPI bands) in human chromosomes. Cytogenet Cell Genet 27:190-193.

Silva WRT, Araújo ED and Scher R (2012) Caracterização do cariótipo de uma população de abelhas Melipona quadrifasciata (Hymenoptera: Meliponini), no município de Brejo Grande/SE. Scientia Plena 8:1-6.

Silveira FA, Melo GAR and Almeida EAB (2002) Abelhas Brasileiras: Sistemática e Identificação. Editora IDM Composição e Arte, Belo Horizonte, 254 p.

Sumner AT (1972) A simple technique for demonstrating centromeric heterochromatin. Exp Cell Res 75:304-306.

Tavares MG, Lopes DM and Campos LAO (2017) An overview of cytogenetics of the tribe Meliponini (Hymenoptera: Apidae). Genetica 3:241-258.

\section{Supplementary material}

The following online material is available for this article:

Figure S1 - DAPI stained metaphases of Melipona paraensis Melipona seminigra pernigra.

Associate Editor: Yatio Yassuda-Yonenaga

License information: This is an open-access article distributed under the terms of the Creative Commons Attribution License (type CC-BY), which permits unrestricted use, distribution and reproduction in any medium, provided the original article is properly cited. 